\title{
Abstract
}

\section{Self-Reported Work Limitation Data: What They Can and Cannot Tell Us}

\author{
Richard V. Burkhauser, Mary C. Daly, Andrew J. Houtenville, \\ and Nigar Nargis
}

Data constraints make the long-term monitoring of the working-age population with disabilities a difficult task. Indeed, the Current Population Survey (CPS) is the only national data source that offers detailed work and income questions and consistently asked measures of disability over a 20-year period. Despite its widespread use in the literature, the CPS and surveys like it have come under attack of late, with critics discounting the results of any research obtained from such data. We put these criticisms in perspective by systematically examining what the CPS data can and cannot be used for in disability research. Based on comparisons with the National Health Interview Survey (NHIS), a data set with much more information on health than the CPS, we find that the work limitation-based definition of disability available in the CPS underestimates the size of the broader population with health impairments in the NHIS, but that the employment trends in these two populations in the NHIS are not significantly different from one another. We then show that the trends in employment observed for the NHIS population defined by selfreported work limitation are not statistically different from those found in the CPS. Based on these findings, we argue (1) that the CPS and other nationally representative employment-based data sets can be used to monitor trends in outcomes of those with disabilities and, (2) that the dramatic decline in the employment of people with disabilities we describe in the CPS during the 1990s is not an artifact of the data.

Published in: Demography, Volume 39, Number 3, 2002. Pages: 541-555

For full text see publisher's website: http://www.popassoc.org/ 